\title{
REFLECTIONS ON: "INDIGENOUS RIGHTS AND INTERESTS IN WiLdCOUNTRY IN AUSTRALIA, BY GHAZALA SHAHABUDDIN
}

\author{
Transforming Cultures eJ ournal, \\ Vol. 3 No 1, February 2008 \\ http:// epress.lib.uts.edu.au/journals/TfC
}

\section{Ghazala Shahabuddin}

Ghazala $^{1}$ is co-editor with Mahesh Rangarajan, of Making Conservation Work, Permanent Black, 2007, reviewed in this volume. She is commenting here after reading the interview with Anthony Esposito (National Manager of the Indigenous Conservation Program, The Wilderness Society) recorded by Heather Goodall, January 2007.

It has been interesting to read about the nuts and bolts of undertaking a large-scale conservation initiative such as the Wild Country programme in Australia. The Wild Country programme is different from any such activity in India in the sense that it covers very large areas of land, deals with the entire range of habitat uses and protection levels and works with a more diverse set of actors in comparison to any programme that can be witnessed in India around this time. Apart from this, it seems to be completely supported in principle by the government as well, despite being run by an NGO.

As other Indian participants might corroborate, such co-management initiatives in India are still very scattered and small-scale and often have little support of forest laws. They have usually been initiated by local communities themselves in response to growing restrictions on resource access, or in response to a localized conservation problem. Most such efforts by scientific NGOs too, are also very small-scale as of now and often end up working in conflict with governmental laws.

\footnotetext{
${ }^{1}$ Ghazala Shahabuddin is an ecologist working on forestry and biodiversity. She has been studying linkages between resource extraction and biodiversity conservation in the Sariska Tiger Reserve, Rajasthan, in relation to protected area management. She also works on issues relating to habitat fragmentation, ecological monitoring and sustainable forest use. She is currently a PhD Fellow at the New India Foundation, Maryland.
} 
There do exist some other government-sponsored initiatives on a larger scale that have met partially with success, such as the Joint Forest Management (JFM) programme which covers 14 million hectares as of 2002. But JFM is not really 'co-management' in the sense that most of the actual decision-making still remains in the hands of the governmental agencies and many of the stakeholders still remain out of the calculations. Above all, JFM was never thought about with biodiversity conservation as one of the primary concerns but more as a 'forest-regeneration-for-biomass-needs' kind of programme. However, JFM has had considerable effectiveness in reaching benefits (mainly in the form of biomass for fodder and fuel) to the target that they were originally aimed at and in restoring a sense of ownership to people while regenerating large stretches of the forested landscape. JFM certainly cannot be dismissed as insignificant either politically or biologically: it can be viewed as something in between a forest conservation programme and a social justice tool and has had mixed success in both respects. There are other possible means of co-management such as the recent inclusion of 'community reserves' and 'conservation reserves' in the conservation laws in India but these have yet to be operationalized on the ground. However, it is feared by many that such new laws might even lead to the undermining of existing people-based efforts at conservation that began spontaneously.

I have a few ideological differences, though, with the aims of the Wild Country Programme. Can conservation be viewed as an effective tool for delivering land justice or vice versa? I would say the jury is still out on this. As a biologist, I am uncomfortable with supporting this notion unconditionally. Experiences the world over indicate that as long as extraction pressures and external conflict levels are low, people are inclined to protect biological resources. But when the needs of livelihood take precedence over those of biodiversity conservation, ultimately biodiversity suffers. There is usually subtle forest modification by the users that allows the 'green cover' to remain but results in 'living dead' ecosystems where a wide range of organisms die out and many of the vital ecological functions of the forest come to a standstill while yet meeting the immediate needs of the people. Thus I would be more comfortable with co-management if it could be scientifically demonstrated to what extent the needs of people could coexist with overall biodiversity conservation. 


\section{Lessons for Indian Situation}

What strikes me to be most significant about the Esposito interview, however, and which has lessons for the Indian situation, is the effort to utilize both the major knowledge streams, Western as well as Aboriginal, in solving the biodiversity conservation problem. As Esposito indicates, Western conservation science has been part of the problem so it needs to be part of the solution as well. He does not wish away the influence of modern science on conservation goals for the landscapes. There is a recognition that neither traditional knowledge nor mainstream biology will be able to save nature by itself.

This is in contrast to the situation in India where most social scientists/activists do not tend to look beyond their discipline and remain sceptical about the use of modern science in conservation management, putting all the onus on traditional knowledge of local people. Similarly, most biologists treat social goals, economic benefits and cultural factors perfunctorily at best, a nuisance to be dealt with to get on with the more important goal of saving wildlife. In a small way, ecological historian Mahesh Rangarajan and I have been together attempting to get these two rather polarized groups in India to talk to each other and to recognize the value of each other's disciplines for a better understanding and problem-solving in the real world. Towards this objective, we have been organizing multi-disciplinary seminars, where for the first time, social scientists, forest managers, biologists and social activists have discussed such controversial issues as the displacement of people from PAs. We have just completed editing a book entitled Making Conservation Work that attempts to look at specific conservation issues using constructive and novel approaches, based on long-term experiences in various corners of India.

Another interesting thing that comes out of Esposito's interview is the widespread recognition of the different types of land uses required for biodiversity conservation in the larger landscape within the Wild Country Programme. The different types of land uses that are recognized range from strictly protected zones to wildlife-friendly agricultural and forestry zones to multiple-use areas where livelihood values of locals are prioritised and highly degraded areas in between that can be restored/used for specific purposes. The recognition that each type of land use is as important to the whole larger mosaic and to the long-term conservation goals is crucial for positive 
interactions across the traditional divide. In such a situation, for instance, even managing green areas of urban centres could be as critical to the mosaic as a strictly protected tiger reserve.

Unfortunately we are still far from reaching such a situation in India: at a recent consultation in New Delhi on the future of wildlife conservation in India, social activists could not see the point of 'inviolate areas' for endangered species while most biologists could not see the biodiversity value of any other type of land use other than strictly protected areas.

\section{Defining Conservation Goals}

Several questions came up in my mind regarding the problem of together defining conservation goals for each stretch of wilderness within the Wild Country Programme. I would be interested to know of successful outcomes where management objectives for a given habitat have been equitably and consensually decided with the entire range of users and stake-holders. I am asking because to me, this is possibly the first step to be taken before the conservation processes are put into place. How difficult or easy is this going to be in the Wild Country programme? Has it been actually attempted anywhere and if so, what has been the outcome?

Defining specific conservation goals for a stretch of ecosystem has to be tackled by intensive discussions and studies involving scientists, aboriginal representatives, social scientists and government. What came up in my mind is the possible institutional framework that has been set up for this purpose in the Wild Country Programme? What would be the institutional options for 'freezing' land use (even if management objectives were to be consensually decided) given rapidly changing economies, populations, local aspirations and commercial extraction pressures? Would such an institutional framework be adaptable enough to return opportunity costs of economic development to local people in the future, as these costs keep multiplying? Or, as an armchair conservationist, am I placing too much importance on formalized institutional frameworks? Perhaps formal institutional frameworks do not finally matter as much in the field and a lot works on understanding once a long-term relationship is forged between partners? 
In a sense, the Wild Country Programme is really a massive and exciting experiment, a microcosm of 'best practices' in conservation whose progress will be keenly watched by conservationists in the developing world. 